\title{
Usage of CFD Modelling for Improving an FCC Riser O peration
}

\author{
T. Patureaux ${ }^{1}$ and D. Barthod ${ }^{1}$ \\ 1 TotalFina Raffinage \& Marketing, CdR, département Procédé et Raffinage, BP 27, 76700 Harfleur - France \\ e-mail: thierry.patureaux@total.com - daniel.barthod@total.com
}

\begin{abstract}
Résumé - Utilisation de la CFD pour améliorer le fonctionnement du riser d'une unité de FCC (craquage catalytique) - On a étudié l'homogénéité du flux de catalyseur régénéré arrivant en amont des injecteurs de charge en bas du riser d'une unité industrielle de craquage catalytique (échantillonnage, carte de températures, gammamétries). Il est apparu qu'une mauvaise distribution avait lieu, due vraisemblablement au coude à la base du riser. Le système d'injection de vapeur en place ne pouvait pas résoudre le problème.

On a analysé la situation par utilisation de la simulation numérique de la mécanique des fluides (CFD, Computational Fluid Dynamics), avec une prise en compte des interactions gaz/solide adaptées au système, et pu ainsi décrire l'écoulement de catalyseur. Un nouveau système d'injection de vapeur a alors été conçu et installé. Des observations de terrain, suite à cette modification, ont montré que le but poursuivi avait été atteint, ainsi que le montre la carte des températures au-dessus des injecteurs de charge.
\end{abstract}

La meilleure homogénéité présentée par l'écoulement de catalyseur se traduit par un meilleur contact catalyseur/charge et donc de meilleures performances de l'unité.

Mots-clés : craquage catalytique, riser, distribution du catalyseur, simulation numérique, écoulements, mécanique des fluides, vapeur de transport.

Abstract - Usage of CFD Modelling for Improving an FCC Riser Operation - The homogeneity of the regenerated catalyst flow upstream of the feed injectors at the bottom of an industrial FCC (Fluid Catalytic Cracking) riser was thoroughly investigated using several techniques (sampling, temperature and $\gamma$-scan survey). It appeared that marked maldistribution was taking place, due to a bend at the bottom of the riser, which could not be corrected by the existing steam injection system.

The situation was analysed by use of CFD (Computational Fluid Dynamics) modelling with an approach adapted to circulating fluidised beds, which was able to describe the catalyst flow pattern and voidage distribution. A new steam injection layout was then designed using the CFD model and implemented. Field observations subsequent to the implementation revealed that the goal had been achieved, as demonstrated by the temperature map above the feed injectors.

The better homogeneity of the catalyst flow resulted in an improved catalyst/feed contacting and better performance of the unit.

Keywords: fluid catalytic cracking, riser, catalyst distribution, CFD, computational fluid dynamics, conveying steam. 


\section{IN TRO DUCTIO N}

Total (now TotalFina) has been deeply involved in FCC for a long time, both as an operator (its first unit in France was put on stream in 1954) and as a licensor since the early 80's, when was developed the original two-stage regenerator process $(\mathrm{R} 2 \mathrm{R})$, as the result of an intensive research in association with IFP.

This process is now licensed by IFP and Stone \& Webster Engineering Corp., with the continuous support of a heavy R\&D program from TotalFina and IFP.

This research effort, aimed at improving the design, operation and reliability of the R2R process, led to a better identification and comprehension of what are the key points of an industrial FCC unit.

A lot of knowledge and experience being then accumulated through research and operation, every opportunity to improve the existing units of TotalFina was seized, especially during major revamps and turnarounds.

This article describes the work that has been done to improve the feed/catalyst initial contacting at the FCC unit in TotalFina refinery near Dunkerque (France), using CFD as a tool for analysing an existing situation and implementing a solution to tackle the problem [1].

\section{BACKGROUND OF THE UNIT}

The FCC unit at TotalFina Dunkerque refinery is an Exxon Flexicracker and was put on stream in 1982. Over the years, it has been subjected to several modifications, such as the change from a dense bed reactor to riser operation, a better catalyst entry in the regenerator, the implementation of highefficiency feed injectors and acceleration steam nozzles, etc., while keeping the general layout of the transfer lines.

In 1994, a series of three major modifications was done on the unit (Fig. 1):

- installation of a new feed injection system with injectors pointing downwards instead of upwards in conventional designs (CCFI);

- a new riser termination device aimed at separating quickly reaction products and catalyst so as to minimise the importance of non-selective post riser cracking reactions;

- a new set of internals in the stripper consisting mainly of a structured packing specially adapted to countercurrent flow of catalyst and stripping gas.

This revamp was very successful in terms of increased products yields and qualities and general profitability of the unit.

As the changes were really a technological breakthrough, a lot of attention was paid to the post-revamp performance evaluation and every part of the unit which had been subjected to a modification was scrutinised and evaluated; within this prospect, attention focused on the riser which, in addition to

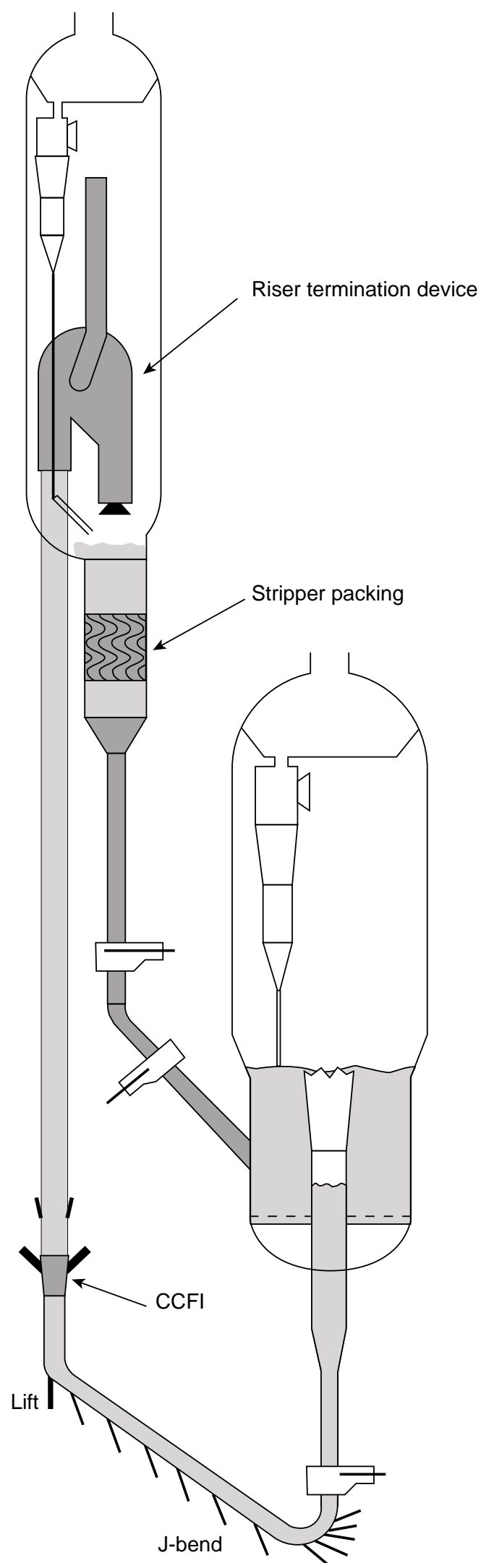

Figure 1

Dunkerque FCC unit configuration. 
the existing instrumentation, had been equipped during the revamp with sampling ports at various levels above the feed injectors.

Some doubts arose concerning the homogeneity of the mixture of feed and catalyst above the injection level, mainly from the indications of the two rows of two thermocouples located at two different elevations above the injector nozzles. It triggered a series of investigations to analyse the situation.

\section{IN VESTIGATION ON CATALYST DISTRIBUTION}

The primary hint came from the thermocouples labelled TJ 2056/2057 and TJ 2058/2059 located respectively 5.5 and $8.5 \mathrm{~m}$ above the injectors level, as shown in Figures 2 and 3.

It appeared clearly that, in spite of a good balance of the feed and dispersion steam through the eight injectors, there was a permanent difference in the temperatures at the two points at the same level, which could be as high as $30-35^{\circ} \mathrm{C}$, when they should have been very close if the mixture catalyst feed had been homogeneous (Table 1).

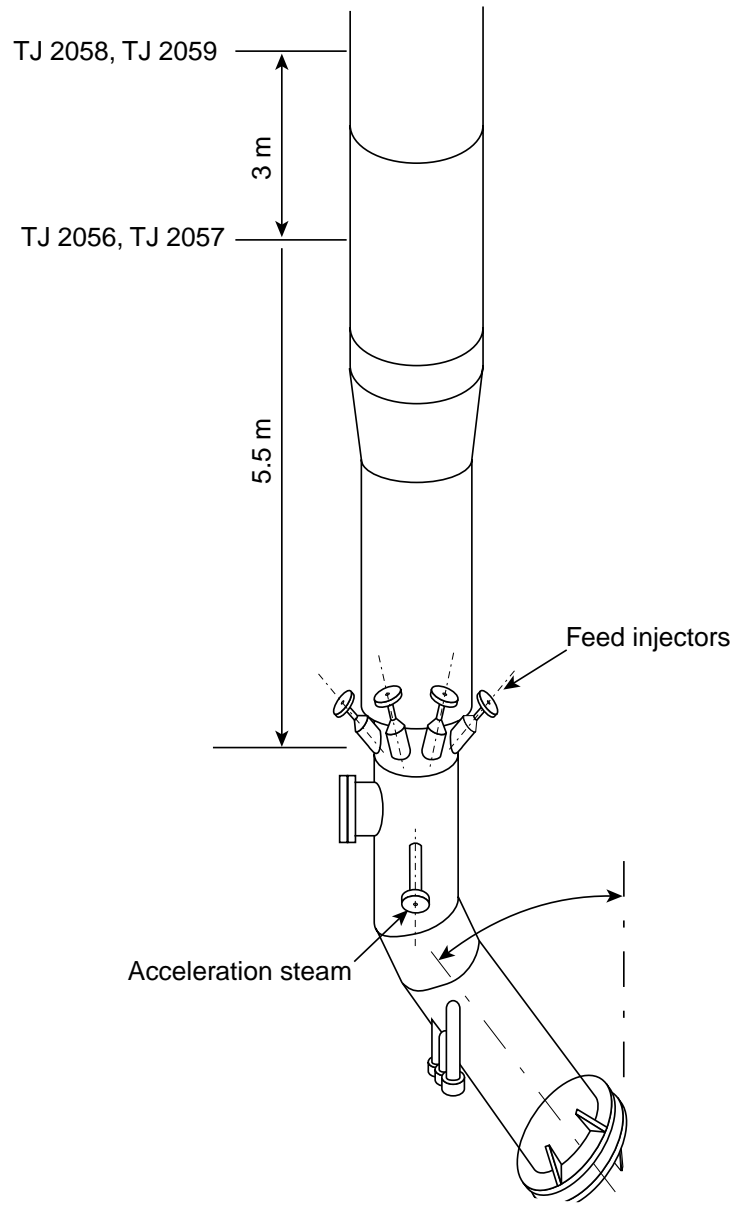

Figure 2

Schema of the riser.

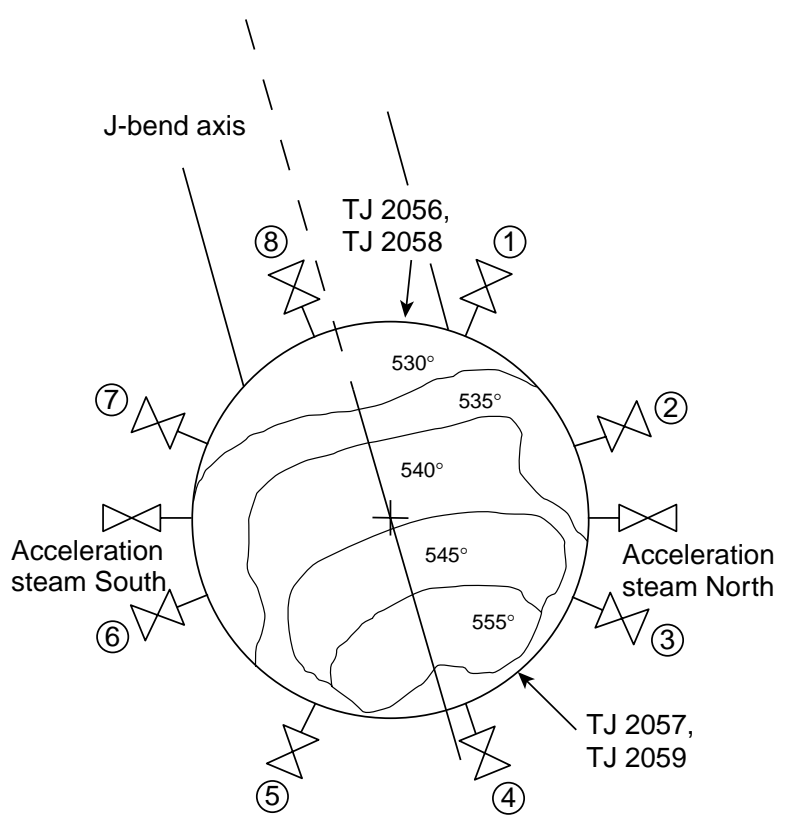

Figure 3

Temperature map of riser and location of thermocouples and injectors.
TABLE 1

\begin{tabular}{l|c|c}
\multicolumn{2}{c}{} & Typical temperatures $\left({ }^{\circ} \mathrm{C}\right)$ \\
\hline $5.5 \mathrm{~m}$ & TJ 2056 & 549 \\
above injector & TJ 2057 & 581 \\
\hline $8.5 \mathrm{~m}$ & TJ 2058 & 534 \\
above injector & TJ 2059 & 562 \\
\hline
\end{tabular}

The temperatures were at the highest above the outside part of the bend at the bottom of the riser; furthermore this misbalance was maintained as the mixture progressed upwards (TJ 2056 and 2058 on one hand, TJ 2057 and 2059 on the other are located on the same vertical lines).

This observation led to the immediate intuitive feeling that when a gas-solid mixture has to follow a bent pipe, it is submitted to a centrifugal effect that sends the solid material towards the outside lane of the turn. In fact, the main cause was that in a slanted upwards transfer line for dense fluidised material, the aeration gas has the tendancy to gather in the upper part of the pipe; at the connection between the slanted part and the vertical one, it will then preferentially escape along the inside lane of the turn.

Several actions were undertaken to assess the real extent of this phenomenon:

- skin temperature survey in the injection zone: the skin temperature of the outside wall of the riser was taken at different levels and locations with a portable infrared thermometer. If it was rather uniform below the injectors, 
it was clearly higher between and above injectors Nos. 4 to 6 , which was coherent with the hypothesis of a preferential flow path of the catalyst;

- a gamma scan at various levels in the injection zone showed again a tendancy for the catalyst to flow in the extrados region, but nothing quantitative nor definite could be obtained by this technique;

- a new test was then designed to confirm the link between the geometry of the J-bend and the catalyst flow pattern. The idea was that a well balanced and symmetrical injection system could not obviously be able to correct a dissymmetry in the catalyst flow.

To have the indications of the wall thermocouples at the same level coming closer together, one had to shut off the feed injector No. 8 (while maintaining the dispersion steam in service); the gap between temperatures shrank then very significantly (Table 2).

TABLE 2

\begin{tabular}{l|c|c}
\hline \multicolumn{3}{c}{ Temperatures close to the wall $\left({ }^{\circ} \mathrm{C}\right)$} \\
\hline & $\begin{array}{c}\text { All injectors } \\
\text { in operation }\end{array}$ & $\begin{array}{c}\text { Injector No. 8 } \\
\text { shut off }\end{array}$ \\
\hline TJ 2057-TJ 2056 & 33 & 6 \\
\hline TJ 2059-TJ 2058 & 28 & 12 \\
\hline
\end{tabular}

It clearly indicated that with a perfectly balanced and close to symmetry system, the catalyst flows preferentially on the opposite lane of the J-bend and even on the right side.

More complete profiles inside the riser were elaborated at $15 \mathrm{~m}$ above the injectors by introducing a movable probe equipped with a thermocouple; the best result concerning the temperature profile flatness was obtained with injectors Nos. 7 and 8 closed (see locations of injectors in Figure 3).

In the mean time, samples were taken in the vapour line to evaluate the consequences on the yield structure at the very outlet of the reaction section.

It was clear enough that with a homogeneous feed/catalyst mixture, even at the expense of a misbalanced feed injection, one was really able to modify the yield structure towards less dry gas $(0.32 \%$ absolute is really significant $)$, with improved selectivities (Table 3).

\section{TABLE 3}

Result of temperature optimisation*

\begin{tabular}{l|c}
\hline Product or property & Absolute changes \\
\hline $\mathrm{H}_{2}-\mathrm{C}_{2}, \mathrm{wt} \%$ & -0.32 \\
$\mathrm{LPG}, \mathrm{wt} \%$ & -0.35 \\
Gasoline, wt $\%$ & +0.90 \\
Conversion, wt $\%$ & +0.20 \\
\hline
\end{tabular}

* Nozzles Nos. 7 and 8 closed.

\section{USAGE OF CFD}

All this experimental investigation on the unit itself, which was not always easy to carry out as it interfered in many circumstances with operation, was sufficient in itself to establish a diagnosis and imagine a permanent solution based on technology. It was also a good opportunity to put into practice all the knowledge and know-how gained in the field of CFD applied to the flow of gas-solid fluidised systems, through the research efforts accomplished jointly by TotalFina and IFP.

The resulting modified code was used, at a 1/3 scale of the exact J-bend configuration upstream of the feed injectors.

The main customisation of the code, necessary for predicting correctly gas/solid flows with FCC catalyst, was done by fitting CFD results to experimental measurements on bubbling fluidised beds (Appendix).

The previsions of the simulation were as expected coherent with the observations, showing clearly that the segregation occurring in the slanted part of the transfer line was indeed the cause of the homogeneity of catalyst flow immediately upstream of the injectors (Fig. 4).

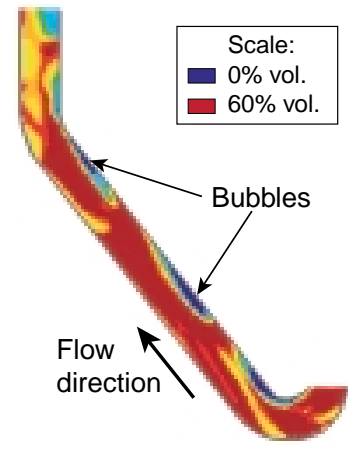

Instantaneous

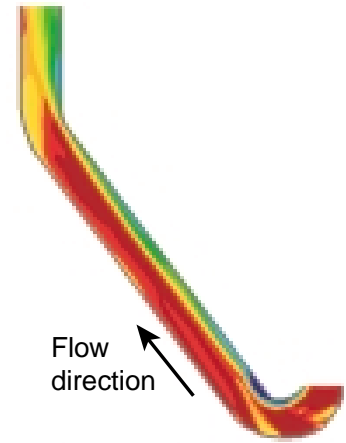

Time-averaged
Figure 4

J-bend catalyst concentrations without redistribution steam.

\section{ELABO RATION AN D IMPLEMENTATION OF A CORRECTIVE MEASURE}

As everything converged to demonstrate that the upflow of regenerated catalyst was not homogeneous on the riser section, and that this heterogeneity could not be corrected by the existing steam system which was almost symmetric with respect to the riser/J-bend plane, this steam system was completed by other nozzles; several solutions were tested initially by CFD to find the optimum position and steam rates for these new nozzles. 


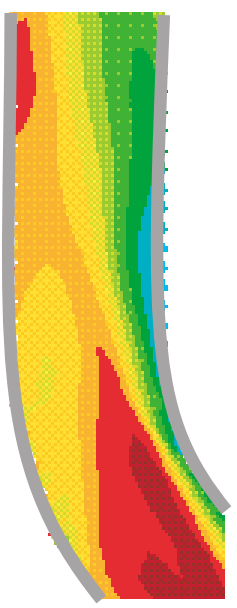

Before, without redistribution steam

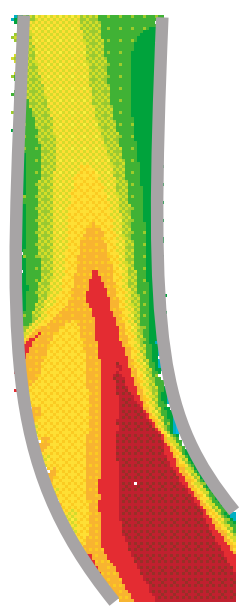

After, with redistribution steam

Figure 5

Catalyst concentration map upstream of the injectors.
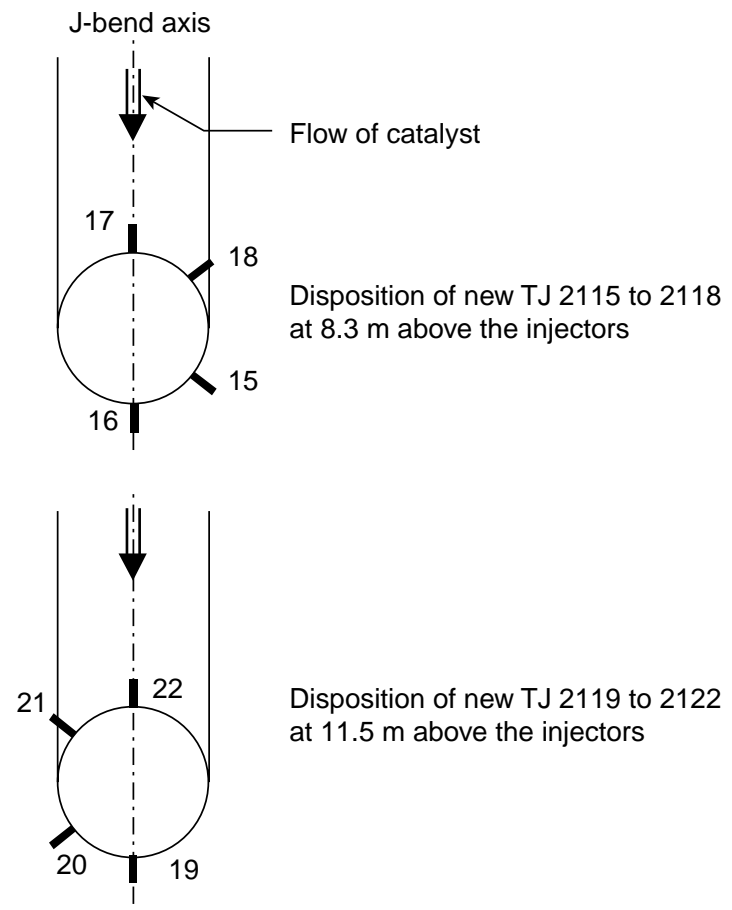

Disposition of new TJ 2119 to 2122 at $11.5 \mathrm{~m}$ above the injectors

Figure 6

Location of the new thermocouples.

Figure 5 shows the CFD-predicted catalyst concentration map upstream of the feed injectors with the new redistribution steam system. It is clear that the time-averaged catalyst flow is more uniform.
In this process it was of course necessary to comply with the room available at the bottom of the riser. These new nozzles were indeed installed during the last revamp in May 1999.

Just to complete the information on the homogeneity of flow in the riser, two additional rows of four thermocouples each were installed respectively at $8.3 \mathrm{~m}$ (TJ 2115 to 2118) and $11.5 \mathrm{~m}$ (TJ 2119 to 2122) according to the disposition of Figure 6.

With all the feed injectors in operation, the maximum difference in temperatures $(\Delta T)$ at the same level has dropped typically to $5^{\circ} \mathrm{C}$ at elevation $8.3 \mathrm{~m}$ and to $7^{\circ} \mathrm{C}$ at $11.5 \mathrm{~m}$.

As shown in Table 4, the temperatures in the outside lane which used to be the highest in the previous situation are now the lowest. It is the demonstration that the corrective effect of the new steam nozzles is effective, but also that a further tuning is necessary.

TABLE 4

\begin{tabular}{l|l|l|l|l}
\hline $\begin{array}{l}\text { Distance } \\
\text { to the feed nozzles (m) }\end{array}$ & \multicolumn{2}{|c|}{8.3} & \multicolumn{2}{c}{11.5} \\
\hline \multirow{3}{*}{ Temperatures $\left({ }^{\circ} \mathrm{C}\right)$} & TJ 2115 & 558 & TJ 2119 & 546 \\
& TJ 2116 & 556 & TJ 2120 & 546 \\
& TJ 2117 & 562 & TJ 2121 & 550 \\
& TJ 2118 & 561 & TJ 2122 & 553 \\
\hline
\end{tabular}

The $\Delta T$ on two opposite vertical lines TJ 2116-TJ 2119 and TJ 2117-TJ 2122 are the same, which means that the reactions progress are the same pace on the two lanes; $\mathrm{C} / \mathrm{O}$ (cat to oil ratio) must be very close in these two regions.

It is probable that a fine tuning of the steam rates on the different nozzles would really level the temperature profiles.

\section{IN FLUEN CE OF CON VEYING AND REDISTRIBUTION STEAM RATES}

The validity of the CFD modelling of the bottom zone of the riser having been established, it has been used to predict the effect of a variation of the conveying steam in the slanted portion and of the redistribution steam.

Figure 7 shows the variation of the local $\mathrm{C} / \mathrm{O}$ ratio at the feed injector levels on the intrados and the extrados following the bend in different cases:

- conveying steam $2 \mathrm{t} / \mathrm{h}$, no redistribution steam: it corresponds to an overaerated transfer line. The segregation is at its worst and the difference in $\mathrm{C} / \mathrm{O}$ is formidable but without too high fluctuations with time;

- conveying steam $1 \mathrm{t} / \mathrm{h}$, no redistribution: the segregation is less, but fluctuations are really high;

- conveying steam $1 \mathrm{t} / \mathrm{h}$, redistribution $1 \mathrm{t} / \mathrm{h}$ : the $\mathrm{C} / \mathrm{O}$ in the opposite regions are very close to the mean values and rather stable. 


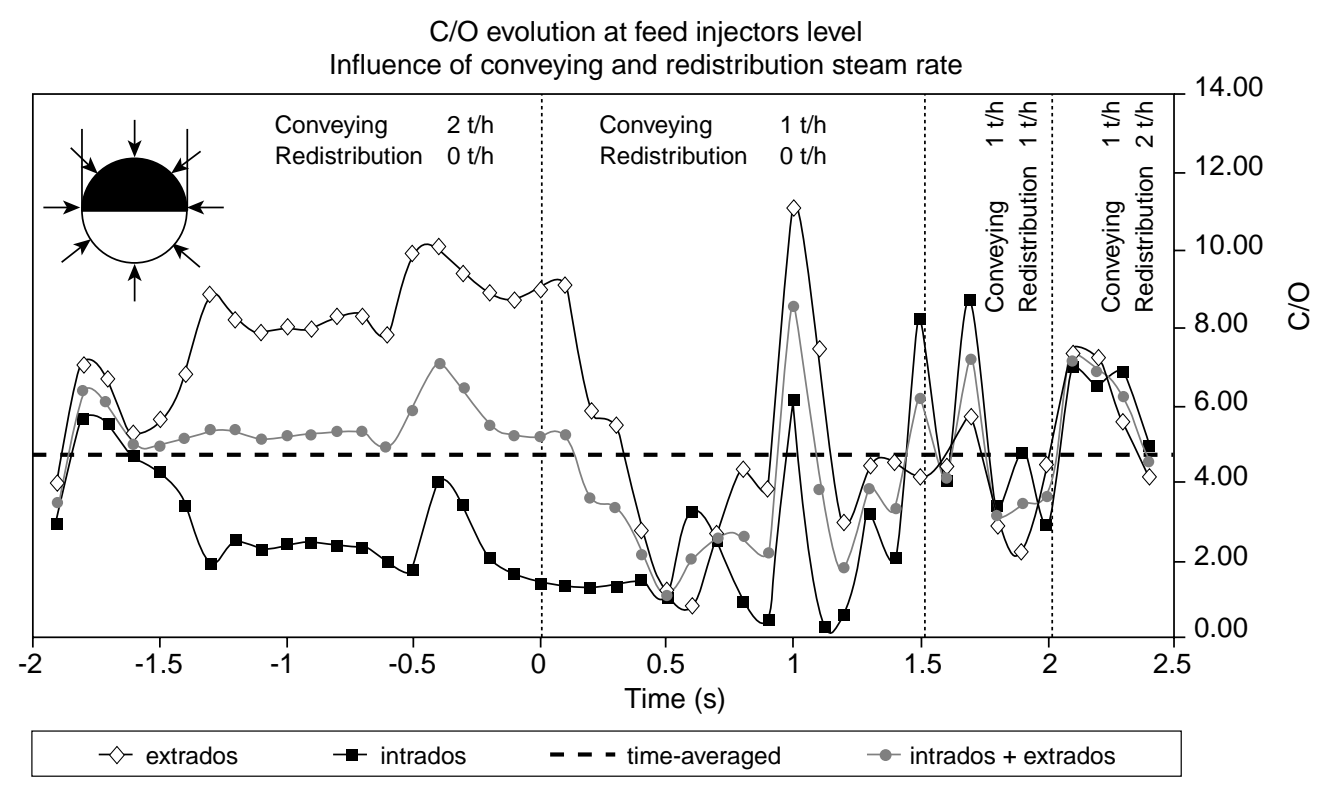

Figure 7

Effect of conveying and redistribution vapours.

These results confirm the effectiveness of the new redistribution steam system, and remind that a slanted upflowing transfer line is very sensitive to an overaeration.

Overaeration can cause a segregation between catalyst and steam upstream of the feed injection level; if not corrected it will be detrimental to the selectivity in the yield structure.

This study confirmed that the radial mixing in a straight riser or fast fluidised bed is rather poor [2-4] and will not be able to correct any default in the initial feed/catalyst contacting zone.

This observation emphasises the major role played by the design of this part of the unit. Once again, CFD along with a good mastery of mass transfer and catalytic aspect is a preferential tool for imagining and implementing an efficient configuration.

\section{CONCLUSIONS}

Several tools were used in this case history to analyse the situation, starting from basic observations such as temperatures to more sophisticated approaches like CFD simulations.

Each of them has its value. Interpretation of temperature maps and surveys was sufficient by itself for conceiving a solution. The coherence between CFD results and observations was in the mean time a confirmation of the validity of the interaction laws introduced in the model and soundness of the analysis of what occurred in the transfer line and the injection zone.
CFD was eventually extremely useful for optimising the technological solution selected and finally implemented.

\section{REFEREN CES}

1 Barthod, D., Mirgain C. and Del Pozzo, M. (1999) Oil and Gas Journal, April 5, 66-69.

2 Geldart, D. (1986) Chap. 7, in Gas Fluidization Technology, J. Wiley \& Sons.

3 Gayan, P., de Diego, L.F. and Adanez, J. (1997) Powder Technology, 94, 163-171.

4 Mastellone, M.L. and Arena, U. (1999) Can. J. of Chem. Eng., 77, April 99, 231.

5 Balzer, G. and Simonin, O. (1993) Proc. of 5th Int. Symp. on Refined Flow Modelling and Turbulence Measurements, Viollet, P.L. (ed.), Presses de l'École nationale des ponts et chaussées, 417-424

6 Balzer, G., Boelle, A. and Simonin, O. (1995) ISEF Fluidisation VIII, Tours, Laguérie, C. and Large, J.F (eds.), 1125-1135.

7 Balzer, G. Simonin, O., Boelle, A. and Lavieville, J. (1996) Circulating Fluidized Bed V, Beijing.

8 Mege, P. and Ferschneider, G. (1994) Rapport IFP No. 41797, IFP.

9 Mege, P. and Ferschneider, G. (1997) Proc. of Seventh International PHOENICS User Conference, Part I, May 1216, Seville, CHAM.

10 Wen, C.Y. and Yu, Y.H. (1996) Mechanics of Fluidization. Chem. Eng. Symp. Series, 62, 100-111.

11 Richardson, J.F. and Zaki W.N. (1954) Sedimentation and Fluidisation: Part I. Trans. Instr. Engrs., 32, 35-53.

Final manuscript received in January 2000 


\section{APPEN DIX}

\section{FCC GAS/ SO UD FLOW MODEL}

In a bubbling fluidised bed, the flow is made up of coexisting very dilute (bubbles) and dense (emulsion) regions. Therefore, the hydrodynamic model must take into account simultaneously the gas-particle and particle-particle interactions in the mean and fluctuating motions.

To simulate such a flow, the approach used is that developed by Simonin [5-7]. This approach, based on the two-fluid model, uses the kinetic theory to account for particle-particle and gas-particle interactions. A 2D version of this model was first implemented into PHOENICS package in order to simulate both dilute and dense FCC gassolid flows $[8,9]$. The results showed that it was necessary to modify this first version of the model to properly simulate these flows. Then it was decided to correct empirically the drag forces by fitting predicted CFD results to experimental measurements on bubbling fluidised beds.

For this purpose, a simple stationary equilibrium 1D model was developed and used. To build this model, one can write both momentum balance and momentum transfer equations:

$$
\begin{gathered}
-\alpha_{1} \frac{\partial P_{1}}{\partial x}+\alpha_{1} \rho_{1} \mathrm{~g}+I_{1}=0 \\
-\alpha_{2} \frac{\partial P_{1}}{\partial x}+\alpha_{2} \rho_{2} \mathrm{~g}+I_{2}=0 \\
I_{2}=-I_{2}=-\alpha_{2} \rho_{1} F_{D} V_{r}
\end{gathered}
$$

$P_{1}$ is the mean pressure of gas, $\alpha_{k}$ is the mean volumetric fraction and $\rho_{k}$ the density of the phase $k$ ( $k=1$ corresponds to the gas, $k=2$ corresponds to the particles). $I_{k}$ is the interphase momentum exchange after subtracting the contribution due to mean gas pressure gradient. $F_{D}$ is the mean drag coefficient $\left(\mathrm{s}^{-1}\right)$ and $V_{r}$ the mean relative velocity.
The particularity of the FCC flows is that $\rho_{2} \gg \rho_{1}$ and, in this case, the forces due to the gas on a single particle are reduced, as we see in these equations, to the mean pressure gradient and to the drag force.

- For dilute gas/solid flows, following the approach of Wen and $\mathrm{Yu}$ [10], we modified the standard law of Richardson and Zaki [11] in order to account for Reynolds number influence and the concentration effects:

$\alpha_{2}<0.2$ :

$$
\begin{gathered}
F_{D}=\frac{3}{4} \cdot \frac{C_{D}}{d} \cdot V_{r} \cdot \alpha_{1}^{-1.65} \cdot f(\operatorname{Re}, d) \\
C_{D}= \begin{cases}\frac{24}{\operatorname{Re}} \cdot\left(1+0.15 \cdot \operatorname{Re}^{0.687}\right) & \text { for } \operatorname{Re}<1000 \\
0.44 & \text { for } \operatorname{Re} \geq 1000\end{cases}
\end{gathered}
$$

$\mathrm{Re}$ is the particle Reynolds number defined by:

$$
\frac{\alpha_{1} V_{r} d}{v_{1}}
$$

$d$ is the mean particle diameter and $f(\mathrm{Re}, d)$ is a correcting factor which depends on $\operatorname{Re}$ and $d$. One can notice that when $f(\operatorname{Re}, d)=1$, we find the Wen and Yu drag force.

- For dense gas/solid flows, a correlation based on Ergun's relation is used in the same way:

$\alpha_{2} \geq 0.2$ :

$$
F_{D}=\left(1.75+\frac{150}{\operatorname{Re}} \cdot \alpha_{2}\right) \cdot \frac{V_{r}}{d} \cdot f(\operatorname{Re}, d)
$$

Then, by substituting the pressure gradient in Equations (1) to (3), one obtains the stationary 1D model used:

$$
\alpha_{1}\left(\frac{\rho_{2}-\rho_{1}}{\rho_{1}}\right) \mathrm{g}-F_{D} V_{r}=0
$$

Finally, comparing the predictions of this 1D model and the measurements from some TotalFina and IFP mock-ups, we have been able to specify the correcting factor $f(\mathrm{Re}, d)$ for different particles. 